INOBIS: Jurnal Inovasi Bisnis dan Manajemen Indonesia

Volume 1, Nomor 1, Desember 2017

Tifa Noer Amelia

\title{
Pengendalian Internal Bisnis Startup Indonesia: Sebuah Konsep
}

\author{
Tifa Noer Amelia \\ Perbanas Institute Jakarta \\ tifanoer@perbanas.id
}

\begin{abstract}
Abstrak
Maraknya perusahaan startup di Indonesia harus diimbangi dengan pengendalian internal pada sistem informasi yang digunakan. Apabila perusahaan tidak memiliki pengendalian internal yang baik, akan timbul resiko penurunan performa perusahaan seperti yang saat ini banyak dialami perusahaan retail. Adapaun kerangka pengendalian internal yang sudah populer digunakan konsultan sistem informasi untuk perusahaan besar yaitu kerangka COBIT, kerangka terintegrasi dan kerangka ERM. Namun, masih sedikit referensi untuk membuat pengendalian internal pada perusahaan kecil dan menengah, sehingga perusahaan rentan terhadap implementasi sistem informasi dan operasional perusahaan. Penelitian mengusung sebuah konsem yang diawali dengan pembuatan aplikasi (beta version) untuk dapat dianalisa dan dikembangkan lebih lanjut, sehingga dapat digunakan dan membantu perusahaan kecil dan menengah untuk menjadi perusaan startup yang kempeten.
\end{abstract}

Kata kunci: Startup, Pengendalian Internal, Sistem Informasi, E-commerce

\section{Pendahuluan}

\subsection{Latar Belakang Penelitian}

Informasi adalah sekelompok pesan yang terdiri dari data-data. Setelah diproses, data menjadi informasi yang dapat mewakili fakta untuk proses pengambilan keputusan. Proses ini tidak bisa berdiri sendiri dan harus bersinergi dengan proses lain yang terkait, misalkan transaksi dari departemen atau divisi satu dengan yang lain, yang kemudian didefinisikan sebagai sebuah sistem. Untuk memastikan bahwa keputusan yang diambil merupakan pilihan yang terbaik, maka suatu informasi harus memenuhi beberap akriteria yaitu relevan, dapat diandalkan, lengkap, abadi, efektif, efisien dan dapat diakses (Hall, 2016; Romney \& Steinbart, 2012).

Apabila tidak memenuhi kriteria tersebut, banyak resiko (risk) dan kejadian (event) yang akan menjadi penghambat jalannya sebuah organisasi karena lemahnya sistem informasi. Beberapa diantaranya terjadi di Indonesia seperti kasus fraud di Indonesia maupun kasus internasional yang marak diberitakan sebagai fraud terbesar dunia. Di Indonesia sendiri setahun terakhir sedang marak pemberitaan mengenai bangkrutnya bisnis retail dikarenakan kurang dapat merespon trend transaksi online maupun E-commerce, seperti Ramayana supermarket, Matahari mall, Hypermarket, Seven eleven, Perusahaan jamu Nyonya Menir, dan sepinya pusat perbelanjaan di kota-kota besar. Perusahaan online yang dianggap dapat mengancam keberadaan perusahaan retail di Indonesia ini mayoritas adalah perusahaan startup yang sudah diakui dunia kesuksesannya. Sebut saja Tokopedia.com, Bukalapak.com, Blibli.com, Traveloka.com dan Blanja.com. Secara keseluruhan, jumlah bisnis startup di indonesia juga masuk tiga besar peringkat dunia (Startupranking, 2017).

Kehandalan pengendalian internal pada sistem informasi tidak hanya tergantung pada auditor saja namun juga seberapa kuat struktur pengendalian yang digunakan (O'Leary, Iselin, 
INOBIS: Jurnal Inovasi Bisnis dan Manajemen Indonesia

Volume 1, Nomor 1, Desember 2017

Tifa Noer Amelia

\& Sharma, 2006). Meskipun demikian, tidak sedikit pula tindakan tidak etis yang terjadi karena tidak tersaring dengan pengendalian yang ada. Hal ini dikarenakan kurangnya komitmen top management, dan tidak adanya kesadaran operational manager and staffs untukmenjalankan pengendalian internal sesuai dengan aturan dan prosedur yang berlaku (Boda \& Zsolnai, 2016).

Peraturan terkait pengendalian internal yang paling berpengaruh adalah Corporate Auditing Accountability and Responsibility Act yang populer dengan istilah Sarbanes Oxley Act (SOX). Lebih detail lagi yang tertera pada pasal 404 tentang manajemen penilaian pengendalian internal yang harus dilakukan secara rutin dan pasal 302 tentang kewajiban korporasi untuk pengendalian laporan keuangannya. Salah satu regulasi yang berpengaruh dalam pengendalian internal adalah Perusahaan dan Audit Akuntabilitas dan Tanggung Jawab Act atau lebih dikenal sebagai Sarbanes Oxley Act (SOX). Pada bagian 404 menyatakan tentang Penilaian Manajemen Pengendalian Internal yang tahunan dan Pasal 302 tentang Tanggung Jawab Perusahaan untuk Laporan Keuangan. Peraturan ini apabila secara bersamaan diimplementasikan dengan pihak-pihak lain yang terkait, maka akan menghasilkan pengendalian internal yang efektif dan efisien. Khususnya pada organisasi dengan sistem informasi yang telah terintegrasi (Gupta, 2008; Martin, Sanders, \& Scalan, 2014).

Pengendalian internal adalah proses yang dilaksanakan dalam sebuah organisasi untuk memperoleh tingkat keyakinan yang memadai dalam perlindungan aset, menjaga pencatatan secara akurat dan wajar, menyediakan informasi yang handal, menyusun laporan sesuai dengan standar yang ditetapkan, mendukung efisiensi operasi, medorong kepatuhan terhadap kebijakan, dan mematuhi hukum yang berlaku. Alat atau kerangka kerja yang digunakan dalam pengendalian internal terdiri dari tiga pendekatan. Kerangka COBIT (control objectives for information and related technology) yang dikeluarkan oleh ISACA (information system audit and control association), integrated framework yang dikeluarkan oleh COSO (committee of sponsoring organization of the treadway commission, dan ERM (enterprse risk management) yang juga diterbitkan oleh COSO (IAI, 2015). Dari ketiga kerangka tersebut, satu dengan yang lainnya memiliki indikator yang berbeda walaupun dalam beberapa aspek ada unsur kesamaan. Diharapkan penelitian ini dapat menggabungkan ketika kerangka kerja, mengevaluasi dan menggabungkan komponen untuk menghasilkan kerangka pengendalian internal yang saling melengkapi dan handal. Untuk mempertahankan system informasi yang baik, diperlukan pengendalian internal yang komprehensif (Laudon \& Laudon, 2014).

\subsection{Pertanyaan Penelitian}

Pertanyaan penelitian ini muncul dari fenomena naiknya popularitas perusahaan startup baik yang berasal dari Indonesia maupun perluasan dari bisnis starup luar negeri yang dalam waktu cukuo singkat mamou menguasai pasar di Indonesia. Tren pasar yang saat ini mengarah ke penggunaan e-commerce membuat perusahaan startup mampu merajai daftar perusahaanperusahaan unggul Indonesia. Tatangan selanjutnya adalah, seberapa jauh perusahaan startup Indonesia menilai pengendaliain internal sistem informasi perusahaan. Apakah manajemen perusahaan merasa perlu melakukan pengendalian internal setelah melakukan implementasi sistem informasi. Bagaimana pengaruh kelayakan sistem informasi pada performa perusahaan. 
INOBIS: Jurnal Inovasi Bisnis dan Manajemen Indonesia

Volume 1, Nomor 1, Desember 2017

Tifa Noer Amelia

\subsection{Batasan Penelitian}

Penelitian akan dibatasi berdasarkan beberapa kriteria. Seraca teritori, penelitian dibatasi pada usaha kecil dan menengah yang masuk dalam kriteria kemetrian Koperasi dan UMKM di Indonesia. Secara cakupan topik, peneliti membatasi pada implementasi tata kelola pengendalian internal perusahaan yang dapat dianalisa menggunakan tiga kerangka pengendalian sistem informasi, COBIT, kerangka terintegrasi, dan kerangka penilaian resiko perusahaan.

\subsection{Tujuan dan Kontribusi Penelitian}

Penelitian memiliki kontribusi pada adanya pengendalian sistem informasi di perusahaan startup Indonesia yang akan membantu usaha kecil dan menengah untuk memiliki potensi bersaing lebih luas dan turut mensejahterakan masyarakat melalui kemampuan pengusaha kecil dan menengah untuk mengelola perusahaan sesuai dengan tuntuan zaman. Dalam hal ini, penelitian akan menghasilkan sebuah kerangka dan platform yang dapat digunakan dan diakses secara daring oleh pengusaha kecil dan menengah di Indonesia sehingga dapat meningkatkan kredibilitasnya untuk bersaing secara luas.

\section{Tinjauan Pustaka}

Banyak penelitian sistem informasi dibidang bisnis berkaitan satu sama lain. Misal pada kurikulum Akuntansi terdapat mata kuliah sistem informasi Akuntansi dan pada kurikulum Manajemen juga terdapat mata kuliah sistem informasi Manajemen. Sistem informasi Akuntansi fokus pada siklus pendapatam, pengeluaran, produksi, keuangan dan pendanaan. Sedangkan sistem informasi Manajemen manajemen pengetahuan, pengembangan sistem informasi, dan manajemen proyek. Walaupun keduanya membahas mengenai pengendalian internal sistem informasi dan aplikasi teknologi (Miller, Proctor, \& Fulton, 2013).

Perusahaan startup menjadi fokus utama dlam penelitian. Kategori perusahaan startup sendiri merupakan bisnis baru yang cepat berkembang yang tujun utamanya adalah memenuhi kebutuhan pasar dengan pemanfaatan kecangihan teknologi, rekayasa sistem informasi terbaik untuk meningkatkan keunggulang perusahaan, baik melalui inovasi, penciptaan platform daring dan internet (Internet if things - IOT) (Ho, Kauffman, \& Liang, 2011; Peters, Rice, \& Sundararajan, 2004; Reardon \& Minten, 2011).

\subsection{Sistem Informasi}

Implementasi pengendalian intenal pada sistem informasi perusahaan merupakan isu yang sangat umum. Hal ini dikarenakan adanya tuntutan dari kelayakan audit internal perusahaan yang mengharuskan perusahaan memiliki kemapanan sistem informasi agar dipandang layang untuk menjalankan usahanya. Namun, hal yang sebaliknya terjadi diperusahaan yang dikategorikan kecil menengah oleh kementerian koperasi dan UMKM. Di Indonesia, UMKM disebut sebagai penggerak perekonomian negara karena mampu penyerap lebih dari $90 \%$ angkatan kerja, namun, kemampuan inovasinya dinilai rendah (T. T. H. Tambunan, 2011). Misal di sektor pertanian, usaha milik asing dianggap lebih produktif dibandingkan dengan bisnis lokal karena kemampuan teknologi yang digunakan lebih tinggi (T. Tambunan, 2007). Dikarenakan alasan rendahnya ketersediaan dana atau kondisi keuangan, sehingga perusahaan kecil menengah enggan untuk mengalokasikan kepada sistem informasi. 
INOBIS: Jurnal Inovasi Bisnis dan Manajemen Indonesia

Volume 1, Nomor 1, Desember 2017

Tifa Noer Amelia

Selanjutnya, usaha dan resiko yang sangat besar akan keberhasilan maupun kegagalan implementasi menjadikan pertimbangan lebih lanjut. Sumberdaya manusia yang tidak mumpuni juga menjadi salah satu alasana keengganan perusahaan kecil menengah untuk mengimplementasikan integrasi sitem informasi. Walaupun keberhasilannya dipercaya mampu meningkatkan performa perusahaan (Muscatello, Small, \& Chen, 2003). Adapun penelitian tedahulu dari ketiga kerangka yang akan digunakan dalam penelitian. Kerangka pengendalian internal untuk menganalisa sistem informasi perusahaan terdiri dari tiga. Yaitu kerangka COBIT, kerangka terintegrasi dan keranka ERM.

Tabel 1: Penelitian terdahulu

\begin{tabular}{|l|l|}
\hline \multicolumn{1}{|c|}{ Penulis/Tahun } & \multicolumn{1}{c|}{ Hasil } \\
\hline (Abu-Musa, 2009) & $\begin{array}{l}\text { Perusahaan di Saudi percaya bahwa implementasi COBIT sangat } \\
\text { baik dilakukan, walaupun pada kenyatanya banyak perusahaan yang } \\
\text { belum menjalankan prosesnya. Mayoritas perusahaan yang sudah } \\
\text { menggunakan dan menjalankan adalah perbankan, intitusi keuangan, } \\
\text { dan perusahaan yang bergerak dibidang jasa. Dari struktur } \\
\text { organisasi, departemen sistem informasi dan teknologi, top } \\
\text { manajemen dan internal auditor merasakan pentingnya COBIT. }\end{array}$ \\
(Bernroider \& & $\begin{array}{l}\text { Kerangka pengendalian dalam literatur akademik cukup langka. } \\
\text { Ivanun, dalam kesuksesan sebuah sistem informasi, dukungan } \\
\text { COBIT dianggap tidak lebih penting dibandingkan dengan skala } \\
\text { proyek dan urusan hosting perusahaan. }\end{array}$ \\
(Chang, Yen, \\
Chang, \& Jan, 2014)
\end{tabular}


INOBIS: Jurnal Inovasi Bisnis dan Manajemen Indonesia

Volume 1, Nomor 1, Desember 2017

Tifa Noer Amelia

\begin{tabular}{|l|l|}
\hline (Martin et al., 2014) & $\begin{array}{l}\text { Kerangka pengendaliain internal COSO merupakan yang paling } \\
\text { banyak digunakan diseluruh dunia. Edisi revisi terbarunya } \\
\text { diharapkan dapat mendeteksi dan meminimalisir potensi terjadinya } \\
\text { fraud. }\end{array}$ \\
\hline
\end{tabular}

\subsubsection{Control Objectives for Information and Related Technology (COBIT) Framework}

COBIT adalah kerangka untuk tatakelola dan manajemen sistem informasi dan teknologi. Bentuknya adalah beberapa toolset yang membantu manajemen menganalisa pengendalian yang dibutuhkan, isu teknis dan resiko bisnis. Bentuk dari kerangka pengendalian internal COBIT tergambar seperti diagram berikut (Hall, 2016; IAI, 2015; Rubino \& Vitolla, 2014b).

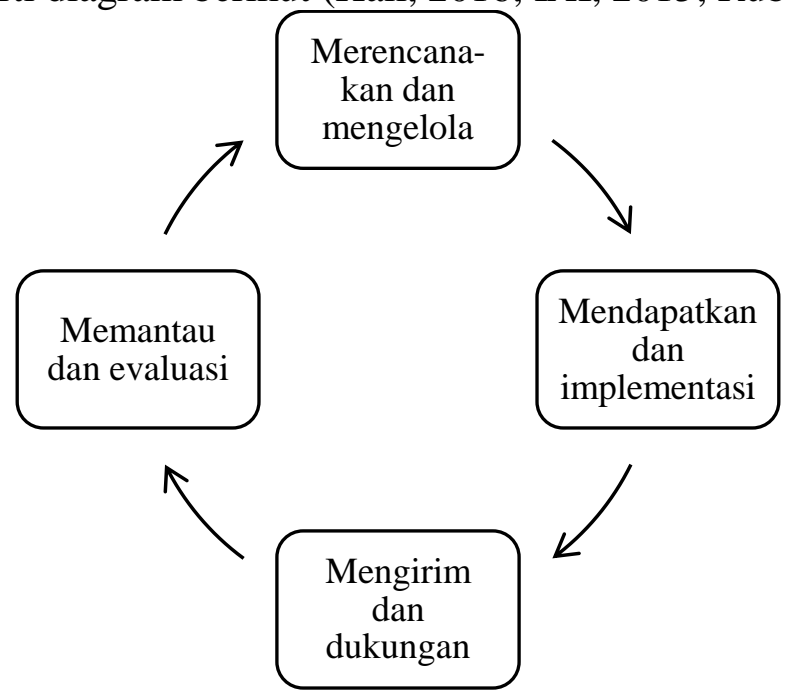

Gambar 1: Kerangka Cobit 5.0

\subsubsection{Intergrated Framework}

Kerangka terintegrasi merupakan instrumen yang paling banyak digunakan untuk menguji kehandalan pengendalian internal sistem informasi. Pengendalian internal dengan kerangka terintegrasi digambarkan sebagai berikut (IAI, 2015; Vaassen, Meuwissen, \& Schelleman, 2009). 
INOBIS: Jurnal Inovasi Bisnis dan Manajemen Indonesia

Volume 1, Nomor 1, Desember 2017

Tifa Noer Amelia

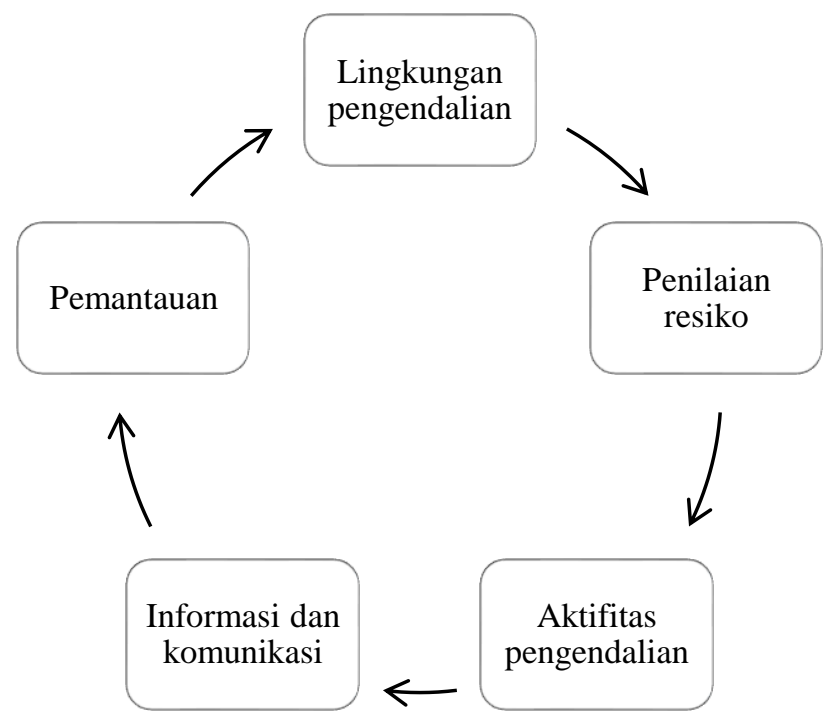

Gambar 2: Kerangka terintegrasi

\subsubsection{Enterprise Risk Management (ERM) Framework}

Enterprise Risk Management (ERM) atau manajemen resiko perusahaan adalah satu dari beberapa instrumen valid intuk mendukung pengendalian internal yang lebih baik (Rubino \& Vitolla, 2014a). is one of the valid instrument to better support internal control in a company. Pengendalian internal dengan kerangka ERM digambarkan sebagai berikut (IAI, 2015).

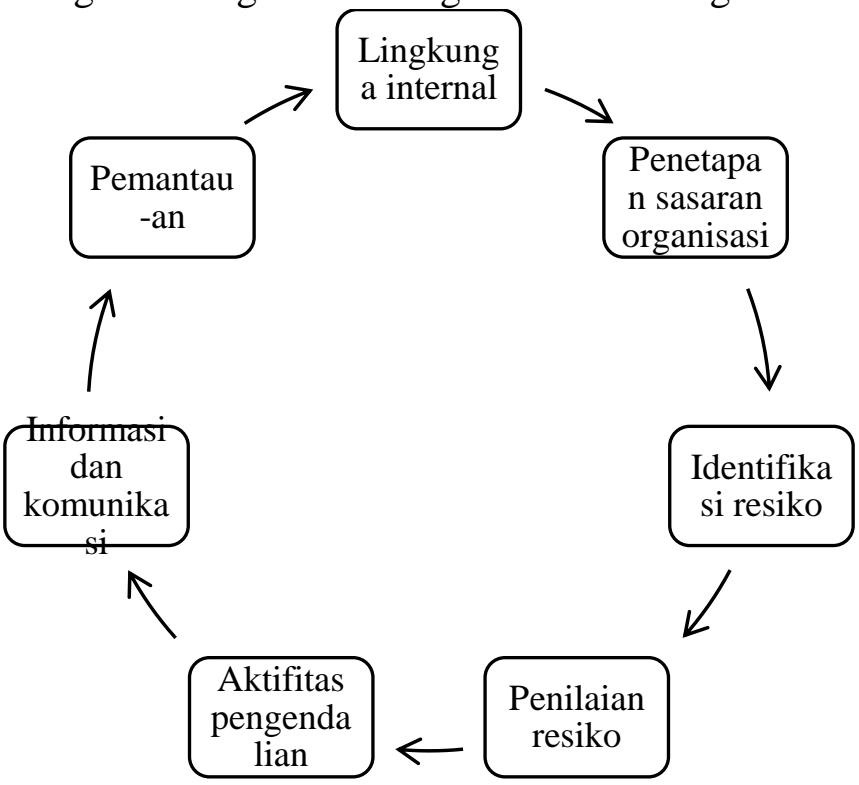

Gambar 3: Kerangka ERM

\subsection{Pengendalian internal}

Pengendalian internal akan membuat suatu sistem informasi perusahaan startup level kecil dan menengah mampu memenuhi unsur efektif, efisien, rahasia, integritas, kesesuaian, keandalan dan kesediaan. Laiknya standar sistem informasi pada perusahaan-perusahaan besar. Kemudian, akan dianalisa bagaimana unsur tesebut berpengaruh terhadap kinerja perusahaan. 
INOBIS: Jurnal Inovasi Bisnis dan Manajemen Indonesia

Volume 1, Nomor 1, Desember 2017

Tifa Noer Amelia

\section{Metode Penelitian}

\subsection{Disain Penelitian}

Adapun pendekatan yang dilakukan dalam penelitian ini adalah metode kualitatif. Pada tahap ini penelitian akan menjabarkan ketiga kerangka pengendalian internal yang umum digunakan untuk menguji pengendalian internal sistem informasi perusahaan yaitu kerangka COBIT, kerangka terintehrasi, dan kerangka ERM (Enterpris Risk Management). Dalam bentuk skema, maupun flowchart yang telah dijabarkan, penelitian akan masuk ke tahap penggabungan. Setelah dilakukan penggabungan sesuai dengan komponen masing-masing kerangka yang terlibat, akan disesuaikan dengan karakter bisnis startup kecil menengah di Indonesia. Kemudian terbentuklah draft yang akan dianalisa bedasarkan wawancara dan diskusi di lapangan baik dengan pelaku usaha maupun para ahli) untuk finalisasi kerangka yang ditawarkan. Untuk selajutnya disebut dengan fase pertama.

Kerangka yang telah di evaluasi pada fase pertama akan dibuatkan versi platform daring, disini dibutuhkan konsultan yang ahli pada bidang pemrograman. Adapun versi beta (sample) dari aplikasi ini dapat dilihat pada Lampiran 2. Untuk selanjutnya disebut dengan fase kedua. Pada fase ini akan dilakukan penyempurnaan dengan cara mengembangkan aplikasi untuk pengendalian internal perusahaan menggunakan platform yang menggunakan fitur penuh (paid version) untuk keamanan dan akses yang lebih mudah.

Hasil akhir dari aplikasi ini adalah penggunaan oleh perusahaan startup dengan gratis. Hasil penilaian pengendalian internal yang didapatkan (generated) dari applikasi dapat digunakan unutk menilai kelayakan sistem informasi perusahaan untuk masuk dan bersaing dalam era bisnis startup. Untuk selanjutnya tahap ini disebut sebagai fase akhir atau fase tiga.

\subsection{Sampel dan Populasi}

Objek penelitian terdiri dari bisnis startup level kecil dan menengah. Bisnis startup adalah bisnis yang baru dirintis maupun bisnis pemula disegala bidang industri. Sedangkan level kecil dan menengah diambil dari Kriteria usaha mikro, kecil dan menengah menurut UU No. 20 Tahun 2008 tentang UMKM.

Usaha Menengah adalah usaha ekonomi produktif yang berdiri sendiri, yang dilakukan oleh orang perseorangan atau badan usaha yang bukan merupakan anak perusahaan atau cabang perusahaan yang dimiliki, dikuasai, atau menjadi bagian baik langsung maupun tidak langsung dengan usaha mikro maupun menengah (level kecil), dan usaha kecil atau usaha besar (level menengah). Usaha ini juga diklasifikasikan menurut jumlah kekayaan bersih atau dengan hasil penjualan tahunan sesuai dengan kriteria yaitu dengan aset lebih dari 50 juta rupiah hingga 500 juta rupiah dengan omzet lebih dari 300 juta rupiah hingga 2,5 miliar rupiah (level kecil) dan lebih dari 500 juta rupiah hingga 10 miliar rupiah dengan omzet lebih dari 2,5 miliar rupiah hingga 50 miliar rupiah.

\subsection{Metode Analisa Data}

Fase pertama akan dilakukan dengan melakukan analisa ketiga kerangka pengendalian internal, eliminasi dan evaluasi (brick and mortar) komponen kerangka yang telah disesuaikan dengan objek enelitian, melakukan diskusi dengan pakar dan pelaku bisnis, serta mengikutkan penelitian pada konferensi-konferensi nasional maupun internasional. Pada fase kedua, melakukan rekayasa kerangka pengendalian internal untk dibuat versi siap pakai (best practice 
INOBIS: Jurnal Inovasi Bisnis dan Manajemen Indonesia

Volume 1, Nomor 1, Desember 2017

Tifa Noer Amelia

application) sekaligus melakukan demo dan simuasi penggunaan aplikasi untuk meningkatkan minat perusahaan yang memiliki potensi untuk menjadi perusahaan startup.

Pada fase terakhir, perusahaan melakukan penilaian (self asessment) dengan menggukan applikasi yang telah siap digunakan (ready to use). Analisa dapat dilakukan perusahaan setelah mendapatkan (generate) hasil dari applikasi.

\section{Hasil yang Diharapkan}

Pada saat ini, aplikasi uji coba (beta version) telah dibuat untuk menunjukan secara visual dari ide pembuatan aplikasi pengendalian internal perusahaan kecil menengah yang memiliki potensi menjadi perusahaan startup yang baik. Aplikasi tersebut sementara dinamakan Tifatools untuk memudahkan identifikasi alat pada app store yang batu tersedia pada platfrom mobile Android dan Windows pada desktop.

Apabila aplikasi ini dapat diimplementasikan dengan baik, perusahaan dapat melakukan penilaian pada pengendalian internasl sistem informasi perusahaan sehingga dapat memenuhi tuhuj kriteria sistem informasi perusahaan yang baik. Yaitu relevan, dapat diandalkan, lengkap, abadi, efektif, efisien dan dapat diakses.

\section{Daftar Pustaka}

Abu-Musa, A. (2009). Exploring the importance and implementation of COBIT processes in Saudi organizations: An empirical study. Information Management \& Computer Security, 17(2), 73-95. doi: doi:10.1108/09685220910963974

Bernroider, E. W. N., \& Ivanov, M. (2011). IT project management control and the Control Objectives for IT and related Technology (CobiT) framework. International Journal of Project Management, 29(3), 325-336. doi: http://dx.doi.org/10.1016/j.ijproman.2010.03.002

Boda, Z., \& Zsolnai, L. (2016). The failure of business ethics. Society and Business Review, 11(1), 93-104. doi: doi:10.1108/SBR-11-2015-0066

Chang, S.-I., Yen, D. C., Chang, I. C., \& Jan, D. (2014). Internal control framework for a compliant ERP system. Information \& Management, 51(2), 187-205. doi: http://dx.doi.org/10.1016/j.im.2013.11.002

Gupta, P. P. (2008). Management's evaluation of internal controls under Section 404(a) using the COSO 1992 control framework: Evidence from practice. International Journal of Disclosure and Governance, 5(1), 48-68. http://dx.doi.org/10.1057/palgrave.jdg.2050073 doi:10.1057/palgrave.jdg.2050073

Hall, J. A. (2016). Accounting information systems 11th ed. Boston: MA Cengage Learning.

Herremans, I. M., Isaac, R. G., Kline, T. J. B., \& Nazari, J. A. (2011). Intellectual Capital and Uncertainty of Knowledge: Control by Design of the Management System. Journal of Business Ethics, 98(4), 627-640.

Ho, S.-C., Kauffman, R. J., \& Liang, T.-P. (2011). Internet-based selling technology and ecommerce growth: a hybrid growth theory approach with cross-model inference. Information Technology and Management, 12(4), 409-429. doi: 10.1007/s10799-0100078-x

IAI. (2015). Modul Chartered Accountant: Sistem Informasi dan Pengendalian Internal. Jakarta: Ikatan Akuntan Indonesia.

Kerr, D. S., \& Murthy, U. S. (2013). The importance of the CobiT framework IT processes for effective internal control over financial reporting in organizations: An international 
INOBIS: Jurnal Inovasi Bisnis dan Manajemen Indonesia

Volume 1, Nomor 1, Desember 2017

Tifa Noer Amelia

survey. Information \& Management, 50(7), 590-597. doi: http://dx.doi.org/10.1016/j.im.2013.07.012

Laudon, K. C., \& Laudon, J. P. (2014). Management information systems : managing the digital firm. Upper Saddle River: New Jersey Pearson Education.

Martin, K., Sanders, E., \& Scalan, G. (2014). The potential impact of COSO internal control integrated framework revision on internal audit structured SOX work programs. Research in Accounting Regulation, 26(1), 110-117. doi: http://dx.doi.org/10.1016/j.racreg.2014.02.012

Miller, K. C., Proctor, T. Y., \& Fulton, B. (2013). Teaching managerial responsibilities for internal controls: Perception gaps between accounting and management professors. Journal of Accounting Education, 31(1), 1-16. doi: http://dx.doi.org/10.1016/j.jaccedu.2012.12.001

Muscatello, J. R., Small, M. H., \& Chen, I. J. (2003). Implementing enterprise resource planning (ERP) systems in small and midsize manufacturing firms. International Journal of Operations \& Production Management, 23(8), 850-871. doi: doi:10.1108/01443570310486329

O'Leary, C., Iselin, E., \& Sharma, D. (2006). The Relative Effects of Elements of Internal Control on Auditors' Evaluations of Internal Control. Pacific Accounting Review, 18(2), 69-96. doi: doi:10.1108/01140580610732822

Peters, L., Rice, M., \& Sundararajan, M. (2004). The Role of Incubators in the Entrepreneurial Process. The Journal of Technology Transfer, 29(1), 83-91. doi: 10.1023/B:JOTT.0000011182.82350.df

Reardon, T., \& Minten, B. (2011). Surprised by supermarkets: diffusion of modern food retail in India. Journal of Agribusiness in Developing and Emerging Economies, 1(2), 134-161. doi: doi:10.1108/20440831111167155

Romney, M. B., \& Steinbart, P. J. (2012). Accounting information systems. Harlow: Pearson.

Rubino, M., \& Vitolla, F. (2014a). Corporate governance and the information system: how a framework for IT governance supports ERM. Corporate Governance: The international journal of business in society, 14(3), 320-338. doi: doi:10.1108/CG-06-2013-0067

Rubino, M., \& Vitolla, F. (2014b). Internal control over financial reporting: opportunities using the COBIT framework. Managerial Auditing Journal, 29(8), 736-771. doi: doi:10.1108/MAJ-03-2014-1016

$\begin{array}{lllll}\text { Startupranking. (2017). Startup Country Rank. } & \text { Retrieved } 2017\end{array}$ http://www.startupranking.com/countries

Tambunan, T. (2007). Transfer of Technology to and Technology Diffusion among Non-farm Small and Medium Enterprises in Indonesia. Knowledge, Technology \& Policy, 20(4), 243-258. doi: 10.1007/s12130-007-9031-7

Tambunan, T. T. H. (2011). Development of small and medium enterprises in a developing country: The Indonesian case. Journal of Enterprising Communities: People and Places in the Global Economy, 5(1), 68-82. doi: doi:10.1108/17506201111119626

Vaassen, E., Meuwissen, R., \& Schelleman, C. (2009). Accounting information systems and internal control. Chichester: John Wiley \& Sons. 